\title{
Baseline Results of the First Healthy Schools Evaluation Among a Community of Young, Irish, Urban Disadvantaged Children and a Comparison of Outcomes With International Norms
}

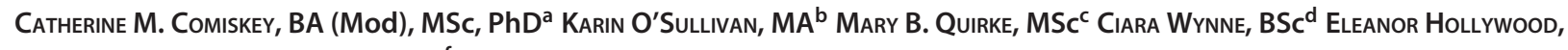
MSc, RGN ${ }^{e}$ Sinead MgILlLoway, PhD $^{f}$

\section{ABSTRACT}

BACKGROUND: In 2008, the Irish Government initiated a pilot Healthy Schools Programme based on the World Health Organization Health Promoting Schools Model among children attending schools officially designated as urban and disadvantaged. We present here the first results on physical and emotional health and the relationship between childhood depression and demographic and socioeconomic factors.

METHODS: The Healthy Schools Programme evaluation was a 3-year longitudinal outcome study among urban disadvantaged children aged 4 to 12 years. Physical and psychological health outcomes were measured using validated, international instruments at baseline. Outcomes at baseline were compared with international norms and where differences were found, results were statistically modeled to determine factors predicting poor outcomes.

RESULTS: A total of 552 children responded at baseline, representing over $50 \%$ of all eligible children available to participate from 7 schools. Findings at baseline revealed that in general, children did not differ significantly from international norms. However, detailed analysis of the childhood depression scores revealed that in order of importance, psychological well-being, the school environment, social support, and peer relations and age were statistically significant predictors of increased childhood depression in children under 12 years of age.

CONCLUSION: Future health and well-being studies in schools among urban disadvantaged children need to broaden their scope to include measures of depression in children under 12 years of age and be cognisant of the impact of the school environment on the mental and emotional health of the very young.

Keywords: child and adolescent health; emotional health; evaluation; mental health; research; school health instruction.

Citation: Comiskey CM, O'Sullivan K, Quirke MB, Wynne C, Hollywood E, MGillloway S. Baseline results of the first healthy schools evaluation among a community of young, Irish, urban disadvantaged children and a comparison of outcomes with international norms. J Sch Health. 2012; 82: 508-513.

Received on August 31, 2011

Accepted on March 21, 2012

$\mathrm{R}^{2}$ eviewing the literature measuring deprivation and child development in the United States, researchers state that in contrast with the apparent precision with which poor children are counted, the

effects of economic deprivation on children are not well understood. Researchers state that the US Census Bureau's measurement of poverty in the United States in 1991 revealed that $21.8 \%$ of American children

\footnotetext{
a'Director of Research and Professor of Healthcare Statistics, (catherine.comiskey@tcd.ie), School of Nursing and Midwifery, Trinity College Dublin, 24 D'Olier St., Dublin 2, Ireland. bProject Manager, (kosulli7@tcd.ie), The Healthy Schools Project, School of Nursing and Midwifery, Trinity College Dublin, 24 D'Olier St., Dublin 2, Ireland. 'Researcher, (quirkema@tcd.ie), The Healthy Schools Project, School of Nursing and Midwifery, Trinity College Dublin, 24 D'Olier St., Dublin 2, Ireland. dResearcher, (wynnec@tcd.e), The Healthy Schools Project, School of Nursing and Midwifery, Trinity College Dublin, 24 D'Olier St., Dublin 2, Ireland. 'Researcher, (hollywem@tcd.e), The Healthy Schools Project, School of Nursing and Midwifery, Trinity College Dublin, 24 D'Olier St., Dublin 2, Ireland. f Director, (sinead.mcgilloway@nuim.ie), Mental Health and Social Research Unit, Department of Psychology, National University of Ireland, Maynooth, County Kildare, Ireland. Address correspondence to: Catherine M. Comiskey, Director of Research and Professor of Healthcare Statistics, (catherine.comiskey@tcd.ie), School of Nursing and Midwifery, Trinity College Dublin, 24 D'Olier St., Dublin 2, Ireland.

This research was commissioned by the Childhood Development Initiative (CDI) for Tallaght West and funded by the Atlantic Philanthropies and the Office of the Minister for Children and Youth Affairs (OMCYA), Ireland.
} 
lived in families in which total income failed to exceed the threshold of US\$13,924 for a family of 4, a measure used to define poverty. Researchers draw upon 2 national studies of poverty on infants. The first was the Infant Health and Development Program (IHDP), an 8-site randomized clinical trial designed to test the efficacy of educational and family-support services and high-quality pediatric follow-up offered in the first 3 years of life in reducing the incidence of developmental delay in lowbirth-weight, preterm infants. The second study was the Panel Study of Income Dynamics, a national study where patterns of family- and neighborhood-level poverty were described in a longitudinal survey of US households by the Survey Research Center at the University of Michigan. It was found that the effects of poverty are cumulative and that family income and poverty status are powerful determinants of the cognitive development and behavior of children, even after accounting for other differences. ${ }^{1}$ The authors found that economic disadvantage not only has a tangible effect on children through the provision of educational resources available to them, but through the detrimental psychological effect it exerts on their parents. Finally, the researchers state that there is little doubt that child poverty, which, they say is much higher in the US than in other Western countries, is scarring the development of that nation's children. ${ }^{1}$ Whereas this review of the literature is extensive, 1 limitation of the work is that authors did not provide any measure of the effect of poverty on children's physical and psychological health.

More recently, researchers in an ongoing study comparing child poverty in the United States with 12 European countries and 2 commonwealth nations, Australia and Canada, found that whereas the number of children in the United States and the 12 European countries were similar (around 72 million), there were as many as 14 million poor American children in comparison to 7 million poor children in comparable European countries. ${ }^{2}$

Drawing on data from the millennium cohort within the UK involving a study of 18,819 babies born between September 2000 and January 2002, researchers also found that the experience of persistent economic hardship as well as very early poverty undermines cognitive functioning at 5 years of age. ${ }^{3}$

Within Ireland, as a direct result of previous research which identified the urgent health needs of children living in poverty and attending primary schools officially designated as urban and most disadvantaged, ${ }^{4}$ the Irish Government with international philanthropic funding initiated a pilot Healthy Schools (HS) programme based on the World Health Organization (WHO) Health Promoting Schools Model in 2006. ${ }^{5}$ The WHO Health Promoting School model has been implemented across the globe from China, ${ }^{6,7}$ to
Canada. ${ }^{8}$ The Irish program sought to improve disadvantaged children's overall health outcomes and increase their access to primary care services. The HS program is a manualized initiative for children 413 years old and is based upon 7 primary outcomes: children demonstrate age-appropriate physical development; children have access to basic health care; children are aware of basic safety, fitness, and health care needs; children are physically fit; children eat healthily; children feel good about themselves and parents are involved in their child's health.

This purpose of this research was to describe the baseline key health and well-being indicators of the first Irish national cohort of over 550 disadvantaged children recruited to the study and compare these children's indicators with national and international norms. Where differences were observed, findings were then statistically modeled to determine factors associated with poor outcomes. The null hypotheses were, first, that there were no differences between the health and well-being of Irish urban disadvantaged children and international norms. Second, there was no relationship between the children's health and well-being outcomes and basic demographic and social factors.

\section{METHODS}

\section{Participants}

The sampling frame consisted of children attending junior infant class (age 4 or 5 years) to 5 th class (age 10-12 years) in 5 intervention schools and 2 comparison schools. The frame definition of 'children attending school' was chosen deliberately as children absent although registered at the school would not necessarily be available for recruitment or be exposed to the HS intervention program. Two comparison schools were chosen for their willingness to participate and for their similarity with the intervention schools. The comparison schools received a minor gratuity for their participation and time. Baseline recruitment occurred in the first semester of the academic year 2008-2009, first follow-up in semester 1 of 2009-2010 and second follow-up in 2010-2011.

Inclusion criteria for children were child attending junior infants to 5 th class in the 2008-2009 academic year; child's parents/guardians agree to their child being included; child is willing to take part in the research process and measurement on the day. The inclusion criteria for parents/guardians were as follows: parents/guardians of children in junior and senior infants willing to complete parent versions of the HS questionnaire on their child's behalf via telephone interview; parents/guardians over age 18 and whose children attend a HS intervention school willing to participate in qualitative interviews as part of the process evaluation. 


\section{Instruments}

The final HS questionnaire, which existed in a parent proxy form for children in junior and senior infant classes ages 4-6 years and in a self-report form for children in 1st to 5 th class ages 7-12 years, consisted of the following:

1. A profile questionnaire, which provided a short demographic background on the child.

2. The internationally validated Kidscreen 27 which recorded the child's quality of life across 5 domains including physical well-being, psychological wellbeing, autonomy and parent relations, social support and peer relations, and school environment. ${ }^{9}$

3. The internationally validated Child Depression Inventory-short version (CDI-S) which is a 10-item questionnaire designed to measure self-reported negative affect. ${ }^{10}$ Only the self-report version was administered at baseline as the proxy parent report was not suitable for children $<7$ years of age.

4. An adapted version of the Health Related Behaviour Questionnaire which is a 31-item questionnaire recording the health behavior of the child across a broad range of health related topics. ${ }^{11}$

5. A body mass index record which recorded weight, height, and waist circumference.

The results for items 1 to 3 are most pertinent here as they relate to the child's general physical and psychological well-being. Items 4 and 5 relate to nutrition, diet, and exercise, and resulting body mass index.

\section{Procedures}

The HS program evaluation was a 3-year longitudinal outcome study among urban disadvantaged children. Health-related outcomes were measured at fixed time points at early-stage implementation and again at 12-month and 24-month follow-up. Children were recruited from intervention and control schools and were measured at the same time points.

\section{Data Analysis}

A number of statistical methodologies were used for the data analysis. The longitudinal HS data required statistical techniques that are suitable for the repeated aspect of the study. However, what is of interest is the outcome results at the baseline stage of the study for all of the children prior to the intervention. Basic descriptive and exploratory statistics were conducted. To ascertain if the baseline outcome result was independent of sex, chi-square tests and Fisher's exact test were applied to the categorical data. With regard to the Kidscreen 27 and CDI-S instruments additional $t$ statistics in line with the instrument guidelines were prepared. The $t$ statistics were compared with the most up-to-date reference or normal population data to determine if the children who were all attending designated disadvantaged schools were in line with average health-related quality of life (HRQoL) and depression scores. For the Kidscreen 27, European reference data were used. ${ }^{12}$ American and Irish reference data were used for the CDI-S. ${ }^{10,13}$ To model predictors of childhood depression, multiple linear regression modeling was used.

\section{RESULTS}

A total of 552 children responded at baseline, representing over $50 \%$ of all eligible children available to participate from the 7 schools. Children ranged in ages from 4 to 12 years, 50\% were male $(\mathrm{N}=276)$ and $50 \%$ were female. Parents completed proxy interviews for 125 children from the junior classes, ages 4 to 7 years. Overall, 427 children from the senior classes, ages 7 to 12 years, completed self-reports. All children were attending urban schools officially designated as the most disadvantaged.

Results for the Kidscreen 27 HRQoL scores by sex and response group (parent proxy or child selfreport) along with the international mean norms and confidence intervals are provided in Table 1. Analysis revealed that all children were within $95 \%$ confidence intervals of the international norms.

A more detailed analysis of the 27 individual Kidscreen questions separately revealed that significant differences were observed in 6 of the 27 items with males generally performing more poorly than females with the exception of physical well-being. However, it was considered prudent to adjust results for multiple testing. To account for multiple testing, the Bonferroni correction was applied to the criterion of .05 to obtain a new criterion of $p \leq .0019$. Originally, differences were found in the questions: have you felt so bad that you did not want to do anything (12.5\%, $\mathrm{N}=27$ males vs $6.4 \%, \mathrm{~N}=13$ females reporting always or often, $\left.\chi^{2}=14.73, \mathrm{df}=4, \mathrm{p}=.005\right)$; have you had enough time for yourself $(58.9 \%, \mathrm{~N}=129$ males vs $67.2 \%$, $\mathrm{N}=139$ females reporting very often or always, $\left.\chi^{2}=12.83, \mathrm{df}=4, \mathrm{p}=.012\right)$; have you been able to talk to your parents when you wanted to $(19.9 \%$, $\mathrm{N}=43$ males vs $13.0 \%, \mathrm{~N}=27$ females reporting never or sometimes, $\left.\chi^{2}=10.01, \mathrm{df}=4, \mathrm{p}=.040\right)$; have you gotten along well with your teachers $(15.4 \%$, $\mathrm{N}=33$ males vs $10.6 \%, \mathrm{~N}=22$ females reporting never or sometimes, $\chi^{2}=9.88, \mathrm{df}=4, \mathrm{p}=.042$ ), and finally have you been physically active $162.4 \%$, $\mathrm{N}=136$ males vs $46.8 \%, \mathrm{~N}=96$ females reporting extremely, $\chi^{2}=12.92$, $\left.\mathrm{df}=4, \mathrm{p}=.012\right)$. Upon Bonferroni adjustment to account for multiple testing, only 1 significant difference emerged: have you been able to pay attention in school $(21.3 \%, \mathrm{~N}=46$ males vs 


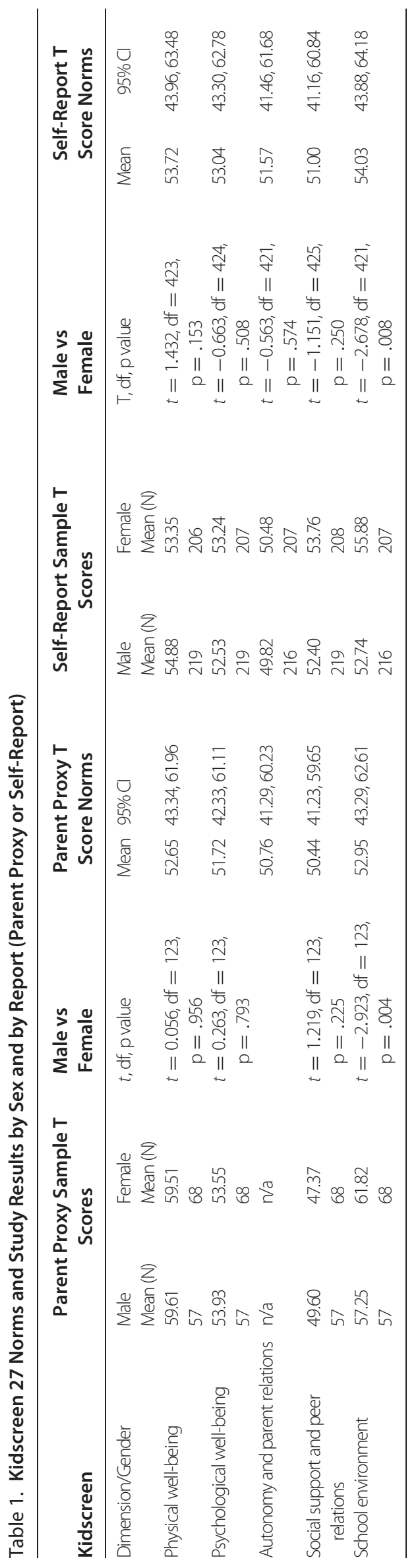

$11.1 \%, \mathrm{~N}=23$ females reporting never or sometimes, $\chi^{2}=17.84, \mathrm{df}=4, \mathrm{p}=.001$ ).

The CDI-S provided a 10 -item single-scale screening tool for depressive symptoms in children 7 years and older. The questions in the inventory have been extracted from the longer CDI assessment tool $^{10}$ and pertain to aspects of emotional well-being including negative mood, interpersonal problems, ineffectiveness, anhedonia or inability to experience pleasure, and negative self-esteem. As the CDI-S is only suitable for use with children 7 years and older, and no parent version exists, no measure was administered to children of Junior and Senior infant classes. The data obtained provided an overall rating of self-report depressive symptoms in relation to normative figures.

The CDI-S tool produces an overall actual score for each child based on their item responses. Each item has 3 optional responses with a score of 0,1 , and 2, increasing in relation to level of symptom severity; hence, higher scores indicate greater levels of depression. As with the Kidscreen-27, the summative score from the 10 items are transformed into T-scores to provide a standardized score. The authors of the CDI-S assessment tool also provide an interpretive guideline for these CDI-S T-scores. Mean T-scores were computed for male $($ mean $=47.38, \mathrm{SD}=9.03$, $\mathrm{N}=197$ ) and female (mean $=48.07, \mathrm{SD}=8.53$, $\mathrm{N}=186$ ) children and no differences were observed $(t=-0.767, \mathrm{df}=381, \mathrm{p}=.444)$.

To explore the CDI-S depression scores in more detail, each of the 10 items was analyzed separately and scores between sexes compared. Results are provided in Table 2. Prior to Bonferroni adjustment for multiple testing, 2 significant differences were observed among the 10 items but these failed to reach significance after the adjustment for the 10 significance tests. It can be seen from the table, however, that, in general, higher proportions of males exhibited some of the more negative emotions.

Comparing the CDI-S results with international and national norms based on Kovacs interpretive scale, ${ }^{10}$ the CDI-S scores for the entire sample indicate that the children in this study fall within the average range of CDI-S scores compared to children of their age in an American population. In Ireland, national normative data have been established for secondary school children ages 12-18 years; ${ }^{14}$ however, norms for a primary school population only exist for 5th and 6th class (in Ireland generally ages 10-13 years) and, furthermore, these only refer to 1 regional population. ${ }^{13}$ Nevertheless, for both of these studies, a raw score of between 6 and 8 out of 20 was used as a cut-off point to identify children as potential cases with depressive symptoms. One study found that $9.6 \%$ of children scored above $7,{ }^{14}$ whereas the other identified $7.4 \%$ of children with a score above $7 .{ }^{12}$ In the current study with a younger population ages $7-12$ years, $6 \%$ 


\begin{tabular}{|c|c|c|c|c|c|c|c|}
\hline CDI Item & Male \% (N) & Female \% (N) & Male \% (N) & Female \% (N) & Male \% (N) & Female \% (N) & $\begin{array}{c}\text { Male vs Female } \\
\chi^{2}, \mathrm{df}, \mathrm{p} \text { value }\end{array}$ \\
\hline \multirow[t]{2}{*}{ 1. I am sad. .. } & \multicolumn{2}{|c|}{ Once in a while } & \multicolumn{2}{|c|}{ Many times } & \multicolumn{2}{|c|}{ All the time } & \\
\hline & $87.9(175)$ & $84.9(158)$ & $9.5(19)$ & $10.2(19)$ & $2.5(5)$ & $4.8(9)$ & $1.574,2, p=.483$ \\
\hline \multirow[t]{2}{*}{ 2. Things will work out. . . } & \multicolumn{2}{|c|}{ Okfor me } & \multicolumn{2}{|c|}{ Not sure if it will work out } & \multicolumn{2}{|c|}{ Nothing ever works out } & \\
\hline & $71.5(143)$ & $75.0(141)$ & $24.0(48)$ & $22.9(43)$ & $4.5(9)$ & $2.1(4)$ & $1.843,2, p=.399$ \\
\hline \multirow[t]{2}{*}{3.1 do... } & \multicolumn{2}{|c|}{ Most things ok } & \multicolumn{2}{|c|}{ Many things wrong } & \multicolumn{2}{|c|}{ Everything wrong } & \\
\hline & $82.5(165)$ & $83.5(157)$ & $14.0(28)$ & $14.9(28)$ & $3.5(7)$ & $1.6(3)$ & $1.429,2, p=.501$ \\
\hline \multirow[t]{2}{*}{ 4. I. . } & \multicolumn{2}{|c|}{ Like myself } & \multicolumn{2}{|c|}{ Do not like myself } & \multicolumn{2}{|c|}{ Hate myself } & \\
\hline & $89.0(178)$ & $169(89.9)$ & $5.5(11)$ & $6.4(12)$ & $5.5(11)$ & $3.7(7)$ & $0.795,2, p=.678$ \\
\hline \multirow[t]{2}{*}{ 5. I feel like crying. . . } & \multicolumn{2}{|c|}{ Once in a while } & \multicolumn{2}{|c|}{ Many days } & \multicolumn{2}{|c|}{ Every day } & \\
\hline & $90.4(178)$ & $86.6(161)$ & $3.6(7)$ & $9.7(18)$ & $6.1(12)$ & $3.8(7)$ & $6.698,2, p=.033$ \\
\hline \multirow{2}{*}{ 6. Things bother me... } & \multicolumn{2}{|c|}{ Once in a while } & \multicolumn{2}{|c|}{ Many times } & \multicolumn{2}{|c|}{ All the time } & \\
\hline & $72.9(145)$ & $78.6(147)$ & $15.6(31)$ & $9.6(18)$ & $11.6(23)$ & $11.8(22)$ & $3.115,2, p=.212$ \\
\hline \multirow[t]{2}{*}{ 7.Ilook... } & \multicolumn{2}{|r|}{ Ok } & \multicolumn{2}{|c|}{$\begin{array}{c}\text { There are some bad things } \\
\text { about my looks }\end{array}$} & \multicolumn{2}{|c|}{ Ugly } & \\
\hline & $86.0(172)$ & $75.5(142)$ & $10.5(21)$ & $19.7(37)$ & $3.5(7)$ & $4.8(9)$ & $7.166,2, p=.027$ \\
\hline \multirow[t]{2}{*}{ 8. I feel alone. .. } & \multicolumn{2}{|c|}{ Do not feel alone } & \multicolumn{2}{|c|}{ Many times } & \multicolumn{2}{|c|}{ All the time } & \\
\hline & $78.8(156)$ & $77.7(146)$ & $15.2(30)$ & $17.6(33)$ & $6.1(12)$ & $4.8(9)$ & $0.644,2, p=.732$ \\
\hline \multirow[t]{2}{*}{9.1 have. .. } & \multicolumn{2}{|c|}{ Plenty of friends } & \multicolumn{2}{|c|}{ Some friends but wish I had more } & Do not ha & e any friends & \\
\hline & $79.0(158)$ & $72.3(136)$ & $17.0(34)$ & $24.5(46)$ & $4.0(8)$ & $3.2(6)$ & $3.364,2, p=.179$ \\
\hline 10. I am sure that. . . & Somebo & dy loves me & Not sure if & ybody loves me & Noboc & loves me & \\
\hline & $82.3(163)$ & $87.8(165)$ & $12.6(25)$ & $8.0(15)$ & $5.1(10)$ & $4.3(8)$ & $2.477,2, p=.290$ \\
\hline
\end{tabular}

of the respondents ( $7 \%$ of males and $4.8 \%$ of females) indicated a score of above 7 .

To understand which factors contribute most to the children's level of depression, a multiple linear regression analysis was conducted with the child's CDI-S T score as the dependent variable and gender, age, the child's Kidscreen subscale score for physical well-being, psychological well-being, autonomy and parent relations, social support and peer relations, and school environment as independent variables. Results of this analysis along with the regression coefficients (standardized beta values) are provided in Table 3. The regression coefficients or standardized beta value describes the effect on the dependent variable of a l-unit increase in the independent variable. Standardizing the beta values also allows for the comparison of effects across the independent variables in the model. The model's $\mathrm{R}^{2}$ value was 0.23 , indicating that $23 \%$ of the variance in the CDI$\mathrm{S}$ scores was explained by the factors; however, the model $\mathrm{F}$ value was significant and as the model was to be used for testing individual factors rather than predicting levels of childhood depression, the model fit was considered adequate.
For each of the significant predictors, it can be seen that the effect size (or regression coefficient) was negative, indicating that as the value of the factor decreased the CDI score increased or worsened, as higher CDI scores indicate greater levels of depression. For example, as the school environment decreases, the CDI score or depression increases. The predictor, psychological well-being, was expected to be significant as it is related to depression; however, the largest significant effect size after psychological well-being was associated with the school environment and social supports and peer relations. Interestingly, sex was not a significant factor but age was. Further descriptive analysis of CDI score by age revealed that 9-year-old children had the highest CDI scores with 2 having scores above 80 .

\section{DISCUSSION}

The principal finding of this study is that urban children ages 4 to 12 in Ireland attending schools officially designated as the most disadvantaged do not, in general, differ significantly in terms of their physical and psychological well-being from international

Table 3. Predictors of Childhood Depression Scores Among Disadvantaged Urban Children Ages 7-12 Years

\begin{tabular}{|c|c|c|c|c|c|c|c|c|}
\hline \multirow[b]{2}{*}{$\begin{array}{l}\text { Dependent } \\
\text { Variable }\end{array}$} & \multicolumn{7}{|c|}{ Independent Predictors and Regression Coefficients and $p$ Values } & \multirow[b]{2}{*}{$\begin{array}{l}\text { Model } \\
\text { F, p }\end{array}$} \\
\hline & $\begin{array}{c}\text { Gender } \\
\beta, p\end{array}$ & $\begin{array}{l}\text { Age } \\
\beta, p\end{array}$ & $\begin{array}{c}\text { Physical } \\
\text { Well-Being } \\
\beta, p\end{array}$ & $\begin{array}{c}\text { Psychological } \\
\text { Well-Being } \\
\beta, p\end{array}$ & $\begin{array}{c}\text { Autonomy and } \\
\text { Parent Relations } \\
\boldsymbol{\beta}, \mathrm{p}\end{array}$ & $\begin{array}{c}\text { Social Support and } \\
\text { Peer Relations } \\
\beta, \mathrm{p}\end{array}$ & $\begin{array}{c}\text { School } \\
\text { Environment } \\
\beta, p\end{array}$ & \\
\hline CDI-ST score & $.07, .127$ & $-.11, .030$ & $-.05, .397$ & $-.26,<.001$ & $-.07, .199$ & $-.12, .025$ & $-.12, .043$ & $15.101,<.001$ \\
\hline
\end{tabular}


norms. However, there is some preliminary evidence that young male disadvantaged children may be performing less well than their female school mates in terms of psychological health. Further analysis of the childhood depression scores for all children aged over 7 revealed that in order of importance, the school environment and social support and peer relations followed by age were significant predictors of increased childhood depression scores.

The key strengths of this study are that all children were recruited from schools officially designated by the Irish Ministry of Education as urban and most disadvantaged and that all instruments used to measure health and well-being had international normative data. The main limitation was that children participating were not selected for inclusion at random. For ethical reasons all children attending the 7 schools were invited to participate and results were shared with parents and teachers. Where any child protection concerns arose, a protocol agreed in advance was enacted and followed up on to ensure that the concern had been appropriately addressed.

\section{IMPLICATIONS FOR SCHOOL HEALTH}

Research has shown that young Irish males are at increased risk of mental health problems, ${ }^{15}$ and the research presented in this study among disadvantaged children between 4 and 12 years old shows that on general health measures, in particular the Kidscreen 27 and the Childhood Depression Inventory Short version, male and female children did not differ. However, upon closer analysis of the components of these instruments, minor differences in sex started to emerge and these need to be closely monitored in the 1- and 2-year follow-up stage of this study. Finally, when childhood depression scores were modeled, the school environment and social supports and peer relations of the children were the most significant predictors of increased depression. This has clear implications for children of disadvantaged communities with disadvantaged schools and poor supports. Future research from this and other school health studies among disadvantaged children must broaden their scope to include the impact of social, peer, parental, and school supports on the health and well-being of young children.

\section{Human Subjects Approval Statement}

This study, its design, instruments, processes, methodology, and all letters of introduction, information leaflets, and consent forms received ethical approval from the Faculty of Health Sciences, Trinity College Dublin, Ireland.

\section{REFERENCES}

1. Duncan G, Brooks-Gunn J, Klebanov P. Economic deprivation and early childhood development. Child Dev. 1994;65(2): 296-318.

2. Rainwater L, Smeeding T. Poor Kids in a Rich Country: America's Children in Comparative Perspective. New York: Russell Sage Foundation; 2003.

3. Schoon I, Jones E, Cheng H, Maughan B. Family hardship, family instability and cognitive development. J Epidemiol Community Health. 2012;66(8):716-722.

4. Axford N, Little M, Duffy L. How Are Our Kids? Report, 2004. Available at: http://connect.southdublin.ie/cdi/images/ stories/Publications/2ndeditionofhowareourkids-pdf.pdf. Accessed July 4, 2011.

5. Denman S, Moon A, Parsons C. The Health Promoting School, Policy, Research and Practice. London: Routledge Falmer; 2002.

6. Lee A, Tsang C, Lee S, To CY. A comprehensive "Healthy Schools Programme" to promote school health: the Hong Kong experience in joining the efforts of health and education sectors. J Epidemiol Community Health. 2003;57(3):174-177.

7. Lee A, Cheng FF, Fung Y, St Ledge L. Can health promoting schools contribute to the better health and wellbeing of young people? The Hong Kong experience. J. Epidemiol Community Health. 2006;60(6):530-536.

8. Physical and Health Education (PHE) Canada. Available at: http://www.phecanada.ca/programs/health-promotingschools. Accessed July 1, 2011.

9. Rajmil L, Herdman M, Fernandez de Sanmamed MJ, et al. Generic health-related quality of life instruments in children and adolescents: a qualitative analysis of content. J Adolesc Health. 2004;34(1):37-45.

10. Kovacs M. The Children's Depression Inventory (CDI) Technical Manual Update. Toronto: Multi-Health Systems Inc.; 2009:31.

11. Balding JW. HRBQ - providing baseline data. Educ Health. 2002;20(4):71.

12. Kidscreen Group Europe. The Kidscreen Questionnaires. Quality of Life Questionnaires for Children and Adolescents. Handbook. Lengerich, Germany: Pabst Science Publishers; 2006:84.

13. Meehan F, Houghton F, Cowley H, Houghton S, Kelleher K. Children's depression, gender and age norms for an Irish national (primary) school population. Ir J Psychol Med. 2008;25(3):88-94.

14. Houghton F, Cowley H, Houghton S, Kelleher K. The Children's Depression Inventory short form (CDI-S) in an Irish context. Ir J Psychol. 2003;24(3):193-198.

15. Lynch F, Mills C, Daly I, Fitzpatrick C. Challenging times: a study to detect Irish adolescents at risk of psychiatric disorders and suicidal ideation. J Adolesc. 2004;27:441-451 